\title{
CPT-II and concomitant hyperfractionated accelerated radiotherapy induce efficient local control in rectal cancer patients: results from a phase II
}

\author{
V Voelter ${ }^{*, 1,5}$, A Zouhair ${ }^{2,5}$, H Vuilleumier ${ }^{3}$, M Matter ${ }^{3}$, H Bouzourene ${ }^{4}$, S Leyvraz', J Bauer', P Coucke $^{2,6}$ and \\ R Stupp' \\ 'Multidisciplinary Oncology Centre, The University of Lausanne Hospitals, Rue du Bugnon 46, CH 101 I, Lausanne, Switzerland; ${ }^{2}$ Department of Radio- \\ Oncology, The University of Lausanne Hospitals, Lausanne, Switzerland; ${ }^{3}$ Department of Surgery, The University of Lausanne Hospitals, Lausanne, \\ Switzerland; ${ }^{4}$ Department of Pathology, The University of Lausanne Hospitals, Lausanne, Switzerland
}

Patients with rectal cancer are at high risk of disease recurrence despite neoadjuvant radiochemotherapy with 5-Fluorouracil (5FU), a regimen that is now widely applied. In order to develop a regimen with increased antitumour activity, we previously established the recommended dose of neoadjuvant CPT-II (three times weekly $90 \mathrm{mg} \mathrm{m}^{-2}$ ) concomitant to hyperfractionated accelerated radiotherapy (HART) followed by surgery within I week. Thirty-three patients ( 20 men) with a locally advanced adenocarcinoma of the rectum were enrolled in this prospective phase II trial (I cT2, 29 cT3, 3 cT4 and 2 I cN + ). Median age was 60 years (range $43-$ 75 years). All patients received all three injections of CPT-II and all but two patients completed radiotherapy as planned. Surgery with total mesorectal excision (TME) was performed within I week (range 2- 15 days). The preoperative chemoradiotherapy was overall well tolerated, $24 \%$ of the patients experienced grade 3 diarrhoea that was easily manageable. At a median follow-up of 2 years no local recurrence occurred, however, nine patients developed distant metastases. The 2-year disease-free survival was $66 \%$ (95\% confidence interval 0.48-0.83). Neoadjuvant CPT-II and HART allow for excellent local control; however, distant relapse remains a concern in this patient population.

British Journal of Cancer (2006) 95, 710-716. doi:10.1038/sj.bjc.6603322 www.bjcancer.com

Published online 29 August 2006

(c) 2006 Cancer Research UK

Keywords: chemoradiotherapy; CPT-I I; distant metastases; neoadjuvant; rectal cancer

Patients with rectal cancer are at high risk of both local and distant relapse despite considerable improvements in the multidisciplinary treatment.

Since the introduction of total mesorectal excision (TME) which includes the resection of the entire mesorectal fascia, local recurrences are reported in $5-17 \%$ of the patients, depending on the experience of the centre, of the surgeon and whether neoadjuvant treatment has been applied or not (Janjan et al, 1998; Kockerling et al, 1998; Kapiteijn et al, 2001; Glimelius et al, 2003; Bosset et al, 2005; Engel et al, 2005; Gerard et al, 2005; Marijnen et al, 2005). This is in sharp contrast to former conventional surgery without additional treatment options, which were associated with local recurrence rates of up to $40 \%$ (Pahlman and Glimelius, 1990; MacFarlane et al, 1993).

In the 1990s, postoperative adjuvant chemoradiotherapy for stage II and III rectal cancer was established based on controlled

\footnotetext{
*Correspondence: Dr V Voelter; E-mail: Verena.Voelter@chuv.ch

${ }^{5} \mathrm{~V}$ and $\mathrm{AZ}$ equally participated in this work and the study was conceived by $P C$ and RS.

${ }^{6}$ Present address: Département de Radio-Oncologie, Centre Hospitalier universitaire de Liège, Sart Tilman, B35, 4000 Liège, Belgique.

Received 24 March 2006; revised 24 July 2006; accepted 25 July 2006; published online 29 August 2006
}

trials indicating a significant improvement of local control and overall survival (Swedish Rectal Cancer Trial, 1997). Neoadjuvant radiotherapy before surgery was proven to significantly decrease the local recurrence rate and to increase survival using an accelerated and hypofractionated schedule delivering $25 \mathrm{~Gy}$ in 5 days $(5 \times 5 \mathrm{~Gy})$ followed by immediate surgery (Swedish Rectal Cancer Trial, 1997). The delivery of conventional radiotherapy with or without chemotherapy before surgery has repeatedly been shown to provide a significant advantage over postoperative, adjuvant treatment in terms of improved local control and reduced toxicity, however, it did not improve overall survival (Pahlman and Glimelius, 1990; Camma et al, 2000; Sauer et al, 2004). Over the past years, emphasis was put on neoadjuvant chemoradiation followed by optimised surgery. It includes all three modalities - surgery, radiotherapy and chemotherapy, albeit variable in sequence and combination (Swedish Rectal Cancer Trial, 1997; Kapiteijn et al, 2001; Bosset et al, 2005; Gerard et al, 2005).

5-Fluorouracil (5FU) has been the only approved chemotherapy agent for colorectal cancer and had been shown to improve outcome in combination with radiotherapy in rectal cancer (NIH, 1990). Irinotecan (CPT-11), a new chemotherapy agent displaying activity in metastatic colorectal cancer was approved in 1996 as a single agent (Rothenberg et al, 1996). In combination with 5FU, it significantly prolongs survival (Saltz et al, 2000). Our rationale of 
integrating an active systemic treatment early in the treatment course of patients with advanced rectal cancer is several-fold. (1) CPT-11 has excellent radiosensitising properties, allowing for better tumour response (Chen et al, 1999). (2) The intact vascular bed enables an optimal delivery of the chemotherapy to the primary tumour and (3) the reduction of tumour size improves the resection quality and potentially allows for better organ preservation. (4) Lastly, micrometastases should be eliminated early in the disease course. Indeed, rectal adenocarcinoma has a high invasive potential with up to $60 \%$ of patients presenting with systemic metastases (mainly lung and liver), either at initial diagnosis or during follow-up (Tepper et al, 2002).

Increased intensity of radiotherapy by hyperfractionation and acceleration (HART) aims at counteracting rapid tumour repopulation. The short treatment time immediately followed by surgery allows for tumour resection before the development of late effects (fibrosis) on normal tissue (Coucke, 1992; Coucke et al, 1995, 2006). In head and neck (Saunders et al, 1999) as well as in lung cancers (Turrisi et al, 1999) HART has shown to improve local control and outcome, and in rectal carcinoma we and others have demonstrated its feasibility (Coucke, 1992; Coucke et al, 1995, 2006; Suwinski et al, 2006). In line with this hypothesis, the interval between the end of radiotherapy and the surgical procedure has been kept short. The Swedish and the Dutch rectal cancer trials demonstrated excellent local control with a short course of neoadjuvant radiotherapy followed by immediate surgery (Swedish Rectal Cancer Trial, 1997; Kapiteijn et al, 2001). However, in particular the latter $5 \times 5$ Gy radiotherapy regimen is associated with considerable local toxicity (Cedermark et al, 1995; Stockholm trial, 1996). With our regimen of hyperfractionated radiotherapy, we aimed at reducing local toxicity while maintaining an intensive short-course regimen.

In a prior phase I trial, we established the neoadjuvant regimen of 3 weekly doses of CPT-11 with concomitant HART followed by immediate surgery (Voelter et al, 2003). The regimen demonstrated promising activity in terms of tumour downstaging. Here, we report the outcome of the phase II cohort of 33 patients treated with this regimen.

\section{PATIENTS AND METHODS}

\section{Patient selection}

Patients with locally advanced rectal cancer stage cT3/4 and/or $\mathrm{cN}+$ without evidence of distant metastases were eligible for this trial. Tumours had to be localised below $15 \mathrm{~cm}$ from the anal verge as measured by flexible recto- and/or colonoscopy. Normal haematological, hepatic and renal function was required for inclusion. Patients must not have had prior chemotherapy nor radiotherapy and no malignant disease during the past 5 years. All patients gave written informed consent before the start of treatment and the protocol was approved by the local Ethics Committee.

\section{Treatment schedule}

Three doses of CPT-11 at $90 \mathrm{mg} \mathrm{m}^{-2}$ were administered as a $30 \mathrm{~min}$ infusion on days 1, 8 and 15. Radiotherapy started on day 8 , and was delivered at $1.6 \mathrm{~Gy}$ per fraction bid ( $6 \mathrm{~h}$ interval) from Monday through Friday for a total dose of $41.6 \mathrm{~Gy}$ (26 fractions over 2.5 weeks). Total mesorectal excision was to be performed within 1 week after the end of the neoadjuvant treatment. Postoperative (adjuvant) chemotherapy was planned to start within 4-6 weeks after surgery. The adjuvant treatment consisted of four cycles of CPT-11. As a result of the prior pelvic radiotherapy, escalating doses of CPT-11 starting at 250,300 and then $350 \mathrm{mg} \mathrm{m}^{-2}$, repeated every 3 weeks were recommended.

\section{Radiotherapy}

Patients were irradiated with a linear accelerator using high-energy photon beams of at least $6 \mathrm{MV}$ (Varian Clinac 2100 or Siemens Primus). The dose prescription was at the intersection of the fields (four-field technique). The homogeneity was within $5 \%$ of the dose prescribed at the isocentre. All fields were to be treated during each fraction. The field margins were defined according to a 'standard field' as described by Gunderson et al (1985). The upper limit was the lower level of the fifth lumbar vertebrae and the lateral margins were $1.5 \mathrm{~cm}$ lateral to the pelvic bone on both sides. The lower limit included the anal canal only if the tumour was located in the low rectum $(0-5 \mathrm{~cm}$ form the anal verge). The exclusion of the anal margin was checked by in vivo dosimetry using thermoluminescent dosimetry (TLD). Corrections of the lower limit were carried out if required.

\section{Assessments and statistical considerations}

Clinical tumour assessment at diagnosis included computed tomography (CT) of the thorax, abdomen and pelvis as well as magnetic resonance imaging (MRI) of the pelvis and/or transrectal ultrasound of the rectum (TRUS). Tumour downstaging was defined as difference between preoperative cT-stage and postoperative ypT-stage using the sixth edition of the AJCC Cancer Staging Manual. As the clinical staging of $\mathrm{N}$-stage has low specificity and sensitivity using standard staging methods (MRI, TRUS, CT) (Kim et al, 1999), the comparison of $\mathrm{cN}$ - and pN-stages remains unreliable and was therefore not performed in the present trial.

During the preoperative period patients were followed for toxicity once a week. Physical examination, full blood count and serum chemistry were performed at least once a week. Toxicity was graded according to National Cancer Institute Common Toxicity Criteria (NCI CTC) version 2.0. Postoperative complications were assessed and reported as 30-day postoperative complication rate. After the end of adjuvant chemotherapy, patients were followed clinically every 3 months for the first 2 years, then every 6 months. Radiological evaluation including a CT scan of the chest, abdomen and pelvis, or abdominal ultrasound and chest X-ray were performed every 6 months for at least the first 3 years. Colonoscopy was performed in regular intervals as recommended by the Swiss Society of Gastroenterology.

The primary end point was local recurrence-free survival, with overall survival, patterns of failure and toxicity as secondary endpoints. We hypothesised that the addition of CPT-11 would increase local control rate. A sample size of 30 was required to detect a reduction of the local failure rate from 15 to $<5 \%$ with a power of $80 \%$ and a standard error of 0.05 . All analyses were performed in the intent-to-treat population. Survival data were computed according to the Kaplan-Meier method (Kaplan and Meier, 1958) from the date of inclusion until the date of disease recurrence or death.

\section{RESULTS}

\section{Patients and treatment delivery}

Between 2000 and 2005, 33 patients (20 men and 13 women) were enrolled. Median age was 60 years with a range of 43-75 years (Table 1). Clinical tumour characteristics are listed in Table 2 and were as follows: One patient with a cT2 tumour, 29 cT3, 3 cT4; 21 patients had clinical evidence of nodal involvement $(\mathrm{cN}+)$. The tumour was located between the anal verge and $15 \mathrm{~cm}$ from the anal verge with a median of $7 \mathrm{~cm}$ (Table 1$)$.

All but two patients completed chemoradiotherapy as scheduled without dose reduction or treatment delay (Table 1). All patients received the planned three CPT-11 infusions before surgery. 
Table I Patient and treatment characteristics

\begin{tabular}{lc}
\hline Patients and tumour & \\
$N=33$ & 20 \\
Male & 13 \\
Female & \\
Age & 60 years \\
Median & $43-75$ years \\
Range & \\
Tumour location & $7 \mathrm{~cm}$ \\
$\quad$ Median & Anal verge $-15 \mathrm{~cm}$ \\
Range & \\
Treatment delivery & $31(94 \%)$ \\
$\quad$ Radiotherapy completed & $33(100 \%)$ \\
Chemotherapy completed & $33(100 \%)$ \\
Surgery & \\
Interval radiotherapy - surgery (days) & 6 \\
Median & $2-15$ \\
Range &
\end{tabular}

Table 2 Clinical (cT) and pathological (ypT) tumour stages

\begin{tabular}{lccc}
\hline & cT2 & cT3 & cT4 \\
\hline ypT1 & & 2 & \\
ypT2 & & 7 & \\
ypT3 & 1 & 18 & 2 \\
ypT4 & 2 & 1 \\
cN+ & & & \\
ypN + & 21 & & \\
\hline
\end{tabular}

Radiotherapy was discontinued early in two patients due to grade 3 diarrhoea after 40 and $28.8 \mathrm{~Gy}$, respectively. The latter patient received postoperatively a complement of irradiation of $20 \mathrm{~Gy}$ ( $2 \mathrm{~Gy}$ daily, five fractions per week) to the sacral concavity and surgical tumour bed combined with $5 \mathrm{FU} 300 \mathrm{mg} \mathrm{m}^{-2}$ day $^{-1}$.

\section{Preoperative chemoradiotherapy}

Overall, the neoadjuvant treatment of HART and CPT-11 was well tolerated. Severe toxicities (grade 3 ) are summarised in Table 3. The majority of patients experienced diarrhoea that was severe in $24 \%$, but usually easily controlled with loperamide and increased fluid intake. Three patients needed temporarily intravenous hydration. Abdominal cramping occurred in $6 \%$ of the patients simultaneously to diarrhoea. Nausea and vomiting were rare as well as severe radiation-related local inflammation (e.g. proctitis). Myelosuppression was mild except in one patient who developed short-lived grade 3 neutropenia after the third CPT-11 dose not requiring any delay in radiotherapy or subsequent surgery. Infections $3^{\circ}$ occurred in three patients: fever without proven infection and neutropenia $1^{\circ}(1)$, Clostridium difficile induced diarrhoea (2); however, no event of neutropenic fever was observed.

\section{Surgery and postoperative complications}

All 33 patients underwent surgery. The median time from the end of radiotherapy to surgery was 6 days (range 2-15) (Table 1). Downstaging of the T-stage was achieved in 11 patients $(33 \%)$ (Table 2). Ten patients (30\%) had nodal involvement at pathological analysis $(\mathrm{ypN}+)$.

Twenty-one patients (64\%) had sphincter-sparing surgery and $12(36 \%)$ needed an abdomino-perineal resection (APR). A
Table 3 Toxicity grade 3, 4 during neoadjuvant radiochemotherapy

Toxicity

Diarrhoea

Infections

Abdominal cramping

Nausea

Cardiovascular*

Proctitis

Bleeding

Neutropenia

*Vasovagal syncope in the context of pyelonephritis $2^{\circ}$.

protective ileostomy had not been systematically applied at the beginning of the study although strongly recommended. However, according to an increased incidence of anastomotic leakage (AL) in this patient population (21\%) (Voelter et al, 2003), the protective ileostomy has been introduced as standard procedure for low anterior resection (overall, 15/21patients had an ileostomy). The AL-rate in the present series is $6 \%$. Overall, severe postoperative complications occurred in $27 \%$ of the patients. This includes two cases of $\mathrm{AL}$ in the 21 patients with low anterior resection (LAR), one of whom did not have an ileostomy. Four patients $(12 \%)$ developed pelvic abscess without evidence of leakage (two with APR, two with LAR and ileostomy). One patient experienced postoperative pulmonary atelectasia and another patient perioperative sepsis with prolonged abdominal wound healing. One 71year old patient died 20 days after surgery due to myocardial infarction and subsequent pneumonia with hypoxia. Another patient needed a definitive colostomy 10 months after LAR due to necrosis of the anastomosis without signs of infection. Of 12 patients with APR, 58\% experienced prolonged perineal wound healing. Five patients suffered from anorexia during the postoperative period (15\%).

Complete resection (R0) was achieved in 26 patients (79\%). The positive circumferential resection margin (CRM) rate was $7 / 33$ (21\%), however, no local recurrence occurred during a follow-up of 34-72 months, but in four of these patients, disease recurred at a distant site.

\section{Adjuvant chemotherapy}

Twenty-five patients (76\%) received adjuvant chemotherapy. At the time the study was conceived, adjuvant 5FU-based chemotherapy was indicated for patients with a postoperative stage III, applicable in our series to only $30 \%$ of patients. In fact, only 13 patients received adjuvant CPT-11 monotherapy, six patients received a combination of CPT-11 and 5FU and five patients were treated with adjuvant infusion of 5FU. No patient experienced severe chemotherapy-related complications despite prior pelvic irradiation. Of the eight patients who did not receive adjuvant chemotherapy, one died, one refused and one patient had ypT1 ypN0 stage without indication for further treatment. In five patients with perioperative complications, no adjuvant chemotherapy was prescribed because of the postoperative delay.

\section{Pattern of relapse}

No local recurrence occurred at a median follow-up of 2 years. Distant relapse (metastases) was observed in nine patients $(27 \%)$, including two of eight patients who did not receive adjuvant chemotherapy and seven of 25 patients who received adjuvant chemotherapy. The disease-free survival at 2 years was $66 \%(95 \%$ confidence interval [CI] 0.48-0.83) (Figure 1). The main distant failure sites were liver and lung (Table 4). One patient was diagnosed with peritoneal metastases during surgery that were resected and the patient is now disease free for $3+$ years. The overall survival is $93 \%(95 \%$ CI $0.84-1.0)$ and the nine patients 
who developed distant metastases had a 3-year survival of $89 \%$ (95\% CI $0.79-1.0)$.

\section{DISCUSSION}

Local failure rates of rectal cancer patients have been substantially reduced with the introduction of more extensive surgery and the use of neoadjuvant chemo- and/or radiotherapy. Relapse rates as

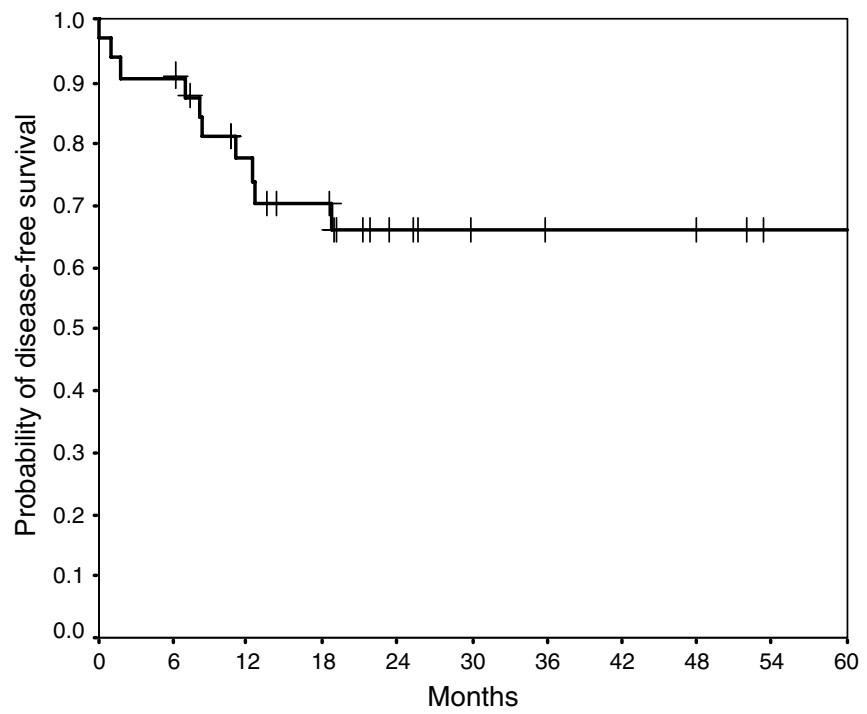

Figure I Disease-free survival.

Table 4 Distant failure sites

\begin{tabular}{lcccc}
\hline UPN & Liver & Lung & Lymph node & Peritoneal \\
\hline 23 & 1 & & & \\
25 & 1 & 1 & & \\
27 & 1 & 1 & & \\
29 & 1 & 1 & & 1 \\
30 & I & 1 & & \\
31 & 1 & & & \\
32 & 35 & & & \\
\hline
\end{tabular}

Abbreviation: UPN, unique patient number. low as $5 \%$ have been reported with TME alone in high volume centres and with very experienced surgeons (MacFarlane et al, 1993). In the Dutch multicentre trial that was also conducted in many community hospitals a local recurrence rate of $11.4 \%$ at 5 years with TME alone was observed (Kapiteijn et al, 2001; Marijnen et al, 2005). This trial confirmed an additional benefit of neoadjuvant short-term radiotherapy even in combination with TME with a reduction of the local relapse rate to only $2.4 \%$ at 2 years and $5.8 \%$ at 5 years. Others have reported high local recurrence rates up to 17\% (Kockerling et al, 1998; Camma et al, 2000; Colorectal Cancer Collaborative Group, 2001; Glimelius et al, 2003; Bosset et al, 2005). This discrepancy can be explained by the heterogeneity of the surgery, because TME was not yet widely applied, and by the variable use of 5FU-based chemoradiotherapy. The importance of chemotherapy has been recently underlined by the results of two randomised trials. They demonstrated that 5FU associated to radiotherapy reduced the rate of local failure, at least in patients who had suboptimal surgery because the trials were initiated before TME had been systematically applied (Bosset et al, 2005; Gerard et al, 2005).

5-Flurouracil has been the mainstay of combined chemoradiotherapy in all large randomised trials (Bosset et al, 2004, 2005; Sauer et al, 2004). But other active chemotherapeutic agents like CPT-11 are now available and should be investigated within a chemoradiotherapy strategy before surgery.

Here, we demonstrate that CPT-11, given concomitantly with neoadjuvant hyperfractionated accelerated radiotherapy followed by TME is well tolerated and resulted in excellent local control, although median follow-up in our report is currently only 2 years. Purposely, CPT-11 was begun 1 week before the start of radiotherapy, aiming at radiosensitisation by administering the first dose of chemotherapy before starting radiotherapy. Furthermore, chemotherapy needed to be completed approximately 2 weeks before the planned surgery in order to avoid occurrence of myelosuppression in the peri- and postoperative period. Despite a relatively short interval between the end of chemoradiotherapy and surgery, downstaging was achieved in one third of the patients and in almost $80 \%$ of patients the resection was complete with negative margins (R0-resection). This compares favourably with other neoadjuvant treatment regimens (Klautke et al, 2001; Chau et al, 2003; Rodel et al, 2003).

The major concern with the use of combined CPT-11 and conventional pelvic radiotherapy has been the occurrence of diarrhoea, a common side effect of both treatments. Our trial suggests that the incidence of severe diarrhoea (24\%) is comparable to that in standard $5 \mathrm{FU}$ regimens, the latter being associated with diarrhoea in up to $23 \%$ of the patients (Table 5) (Minsky et al,

Table 5 Toxicity of neoadjuvant chemo/radiotherapy trials

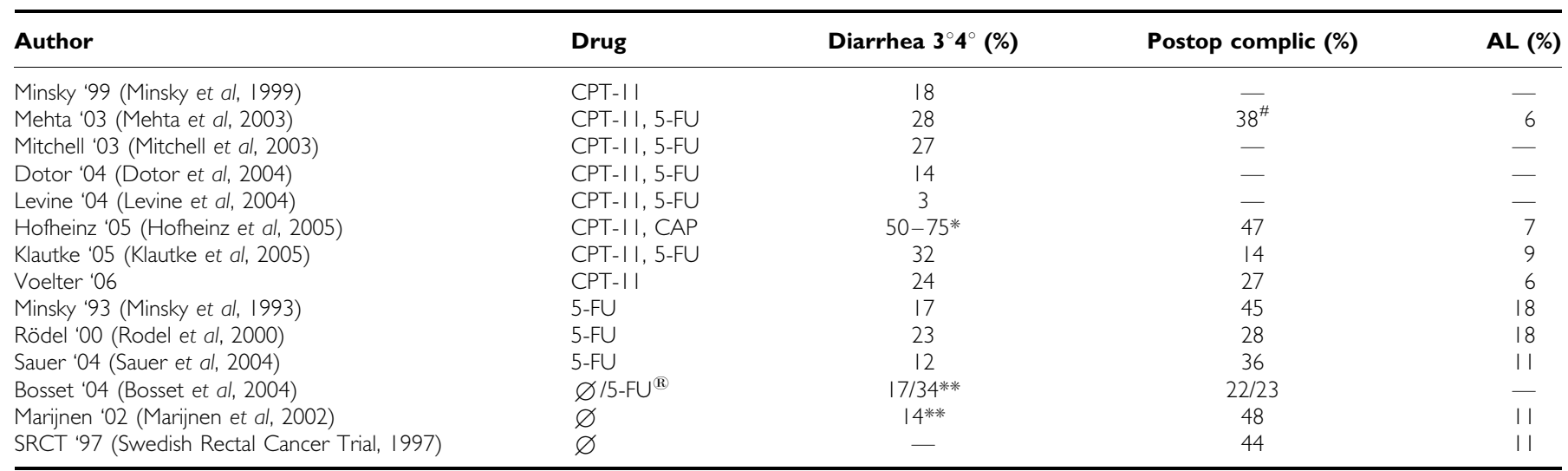

Abbreviations. Postop complic, postoperative complication rate; AL, anastomotic leakage; 5-FU, 5 Fluorouracil; CPT-II, irinotecan; CAP, Capecitabine. Fields without values correspond to no reported data. ${ }^{\#}$ Excluding three patients with postoperative anaemia. *Grade I - 2. ***ade 2 . ${ }^{\circledR}$ Randomised phase III. 
1993; Rodel et al, 2000; Bosset et al, 2004; Sauer et al, 2004). Other trials investigating CPT-11 have shown similar results to ours (Minsky et al, 1999; Mehta et al, 2003; Mitchell et al, 2003; Dotor et al, 2004; Levine et al, 2004; Hofheinz et al, 2005; Klautke et al, 2005). The severity of diarrhoea is also influenced by the irradiation technique. It has been reported that $20-35 \%$ of the patients develop diarrhoea $\geqslant$ grade 2 when treated with a conventional radiotherapy technique using large irradiation fields (Minsky et al, 1995; Bosset et al, 2004).

The overall incidence of postoperative complications is $27 \%$ and is in the range of what has been observed with 5FU-based protocols (Swedish Rectal Cancer Trial, 1997; Rodel et al, 2000; Ngan et al, 2001; Marijnen et al, 2002; Mehta et al, 2003; Bosset et al, 2004). Recently, the large randomised German trial on chemoradiotherapy reported a $36 \%$ postoperative complication rate (Table 5) (Sauer et al, 2004). The rate of anastomotic leakage $(\mathrm{AL})$ after low anterior resection and TME is usually in the range of $6-18 \%$ depending on the series and whether protective ileostomy has been applied or not (Swedish Rectal Cancer Trial, 1997; Rodel et al, 2000; Marijnen et al, 2002; Mehta et al, 2003; Sauer et al, $2004)$. The AL rate of $6 \%$ in our trial compares favourably and indicates that the administration of neoadjuvant CPT-11 with radiotherapy is safe.

Delayed perineal wound healing is common after APR and neoadjuvant radiotherapy. It has been described to occur in about $1 / 3$ of the patients (Pahlman and Glimelius, 1990; Kapiteijn et al, 2001; Marijnen et al, 2002). In the present series, the duration of perineal wound healing was prolonged in more than half of the patients who underwent APR. This is likely due to the use of CPT11. Ultimately, the wound healed in all seven patients.

Despite the use of neoadjuvant and adjuvant chemotherapy the incidence of distant metastases has not been reduced during the last decades. Distant failure rates of $30-40 \%$ are consistently reported throughout all large phase II and III trials and account for the poor outcome of patients with locally advanced rectal cancer compared to patients with colon cancer (Sanfilippo et al, 2001; Marijnen et al, 2003b; Sauer et al, 2004). By 5 years, approximately one third of the patients will die of their disease mainly due to the occurrence of distant metastases (Tepper et al, 2002; Bosset et al, 2005; Marijnen et al, 2005).

In the present trial, a total cumulative dose of neoadjuvant CPT11 of $270 \mathrm{mg} \mathrm{m}^{-2}$ was administered and three quarters of the patients received four cycles of adjuvant chemotherapy. Nevertheless, this did not prevent a $32 \%$ incidence of distant metastases. However, by today's standards the patients in this trial may not have received optimal adjuvant therapy. Recently, combination chemotherapy with infusion of $5 \mathrm{FU}$ and oxaliplatin has been shown to be superior to infusion of 5FU alone in patients with stage II and III colon cancer (Andre et al, 2004), while the combination of $5 \mathrm{FU}$ and $\mathrm{CPT}-11$ failed to demonstrate a similar benefit for the combination (Van Cutsem et al, 2005). At the time the trial was conceived, adjuvant chemotherapy with bolus 5FU and leucovorin was indicated only for patients with postoperative stage III colorectal cancer, representing only $30 \%$ of the patients in the current trial. However, at that time CPT-11 was emerging as a promising new agent with significant activity in second- and firstline therapy of metastatic colorectal cancer. We purposely wanted to expose the patient to the same chemotherapy agent throughout the first-line therapy.

Interestingly, more than half of the patients who had minimal or involved circumferential resection margins consecutively developed distant metastases, while no local recurrence occurred. The majority of these patients had undergone an abdomino-perineal resection. Positive circumferential resection margin involvement is well known to be an important risk factor for disease recurrence, both for distant metastases and/or locally (Nagtegaal et al, 2002; Marijnen et al, 2003a,b). This seems to be particularly frequent after abdomino-perineal resection (Marijnen et al, 2005).

Overall, the association of positive CRM and distant failure suggests that an aggressive biology of the disease leads to early micrometastatic spread while efficient local treatment has prevented local relapse. This is further reinforced by the observation that none of the nine patients who developed distant metastases in this series had a local recurrence at 3 years of followup.

These results stress the importance of delivering potent systemic agents early in the treatment course in order to diminish the incidence of distant metastases and to improve the outcome of patients with locally advanced rectal cancer. Future trials should aim at developing regimens with more active chemotherapy including novel targeted agents. In parallel, radiotherapy techniques have to be adapted in order to spare a maximum of surrounding healthy tissue. Intensity modulated radiation therapy is one of these new techniques. For a more conformal approach, a better definition of target volume is a prerequisite. Therefore, MRI and PET-CT have to be evaluated for their role in determining tumour target volumes with high accuracy.

\section{ACKNOWLEDGEMENTS}

We thank the treating physicians and oncologists who referred patients to the trial for patient care and supporting the study as well as the staff of the Multidisciplinary Oncology Centre for continuous support. The authors like to thank Frances Godson for the critical review of the manuscript.

This trial was supported in part by an unrestricted grant and drug supply by Aventis (Switzerland) and subsequently Pfizer (Switzerland).

\section{REFERENCES}

Andre T, Boni C, Mounedji-Boudiaf L, Navarro M, Tabernero J, Hickish T, Topham C, Zaninelli M, Clingan P, Bridgewater J, Tabah-Fisch I, de Gramont A (2004) Oxaliplatin, fluorouracil, and leucovorin as adjuvant treatment for colon cancer. $N$ Engl J Med 350: 2343-2351

Bosset J, Calais G, Mineur L, Maingon P, Radosevic-Jelic L, Daban A, Bardet E, Beny A, Ollier J, Collette L (2005) Preoperative radiation (Preop RT) in rectal cancer: effect and timing of additional chemotherapy (CT) 5-year results of the EORTC 22921 trial. J Clin Oncol, ASCO Annual Meeting Proceedings 23, No. 16S, Part I of II (June 1 Supplement): 3505

Bosset JF, Calais G, Daban A, Berger C, Radosevic-Jelic L, Maingon P, Bardet E, Pierart M, Briffaux A (2004) Preoperative chemoradiotherapy versus preoperative radiotherapy in rectal cancer patients: assessment of acute toxicity and treatment compliance. Report of the 22921 randomised trial conducted by the EORTC Radiotherapy Group. Eur J Cancer 40: $219-224$

Camma C, Giunta M, Fiorica F, Pagliaro L, Craxi A, Cottone M (2000) Preoperative radiotherapy for resectable rectal cancer: a meta-analysis. JAMA 284: $1008-1015$

Cedermark B, Johansson H, Rutqvist LE, Wilking N (1995) The Stockholm I trial of preoperative short term radiotherapy in operable rectal carcinoma. A prospective randomized trial. Stockholm Colorectal Cancer Study Group. Cancer 75: 2269-2275

Chau I, Allen M, Cunningham D, Tait D, Brown G, Hill M, Sumpter K, Rhodes A, Wotherspoon A, Norman AR, Hill A, Massey A, Prior Y (2003) Neoadjuvant systemic fluorouracil and mitomycin $C$ prior to synchronous chemoradiation is an effective strategy in locally advanced rectal cancer. Br J Cancer 88: 1017-1024

Chen ZS, Sumizawa T, Furukawa T, Ono K, Tani A, Komatsu M, Akiyama S (1999) An enhanced active efflux of CPT-11 and SN-38 in cisplatinresistant human KB carcinoma cells. Cancer Lett 138: 13-22 
Colorectal Cancer Collaborative Group (2001) Adjuvant radiotherapy for rectal cancer: a systematic overview of 8,507 patients from 22 randomised trials. Lancet 358: $1291-1304$

Coucke PA (1992) Postoperative radiation therapy for rectal cancer: an interim analysis of a prospective, randomized multicenter trial in The Netherlands. Cancer 69: 3016-3017

Coucke PA, Notter M, Stamm B, Matter M, Fasolini F, Schlumpf R, Matzinger $\mathrm{O}$, Bouzourene $\mathrm{H}$, on behalf of all surgeons from public hospitals and private clinics (2006) Preoperative hyperfractionated accelerated radiotherapy (HART) in locally advanced rectal cancer (LARC) immediately followed by surgery. A prospective phase II trial. Radiother Oncol 79: 52 - 58

Coucke PA, Sartorelli B, Cuttat JF, Jeanneret W, Gillet M, Mirimanoff RO (1995) The rationale to switch from postoperative hyperfractionated accelerated radiotherapy to preoperative hyperfractionated accelerated radiotherapy in rectal cancer. Int J Radiat Oncol Biol Phys 32: $181-188$

Dotor E, Navarro M, Vega M, Sánchez-Rovira P, Cervantes A, García J, Suárez M, Aranda E, Asensio D, Garcia A, Instituto Catalán de Oncología, HdL-B, Spain; Hospital Marqués de Valdecilla, Santander, Spain; Hospital Ciudad de Jaén, Jaén, Spain; Hospital Clínico de Valencia, Valencia, Spain; Hospital Ramón y Cajal, Madrid, Spain; Hospital del Mar, Barcelona, Spain; Hospital Reina Sofía, Córdoba, Spain; Prasfarma/ Almirall, Barcelona, Spain; Aventis Pharma, S.A., Madrid, Spain (2004) Irinotecan (CPT-11) and 5-fluorouracil (5-FU) concomitantly with preoperative radiotherapy (RT) in patients (pts) with locally advanced resectable rectal cancer. Updated results of a phase II study. J Clin Oncol, ASCO Annual Meeting Proceedings (Post-Meeting Edition) 22: 4179

Engel J, Kerr J, Eckel R, Gunther B, Heiss M, Heitland W, Siewert JR, Jauch KW, Holzel D (2005) Influence of hospital volume on local recurrence and survival in a population sample of rectal cancer patients. Eur J Surg Oncol 31: $512-520$

Gerard J, Bonnetain F, Conroy T, Chapet O, Bouche O, Closon-Dejardin M, Untereiner M, Leduc B, Francois E, Bedenne L (2005) Preoperative (preop) radiotherapy $(\mathrm{RT})+5 \mathrm{FU} /$ folinic acid (FA) in $\mathrm{T} 3-4$ rectal cancers : results of the FFCD 9203 randomized trial. J Clin Oncol, ASCO Annual Meeting Proceedings 23, No.16S, Part I of II (June 1 Supplement): 3504

Glimelius B, Gronberg H, Jarhult J, Wallgren A, Cavallin-Stahl E (2003) A systematic overview of radiation therapy effects in rectal cancer. Acta Oncol 42: $476-492$

Gunderson LL, Russell AH, Llewellyn HJ, Doppke KP, Tepper JE (1985) Treatment planning for colorectal cancer: radiation and surgical techniques and value of small-bowel films. Int J Radiat Oncol Biol Phys 11: $1379-1393$

Hofheinz RD, von Gerstenberg-Helldorf B, Wenz F, Gnad U, KrausTiefenbacher U, Muldner A, Hehlmann R, Post S, Hochhaus A, Willeke F (2005) Phase I trial of capecitabine and weekly irinotecan in combination with radiotherapy for neoadjuvant therapy of rectal cancer. J Clin Oncol 23: $1350-1357$

Janjan NA, Khoo VS, Rich TA, Evetts PA, Goswitz MS, Allen PK, Skibber JM (1998) Locally advanced rectal cancer: surgical complications after infusional chemotherapy and radiation therapy. Radiology 206: $131-136$

Kapiteijn E, Marijnen CA, Nagtegaal ID, Putter H, Steup WH, Wiggers T, Rutten HJ, Pahlman L, Glimelius B, van Krieken JH, Leer JW, van de Velde CJ (2001) Preoperative radiotherapy combined with total mesorectal excision for resectable rectal cancer. $N$ Engl J Med 345: 638- 646

Kaplan E, Meier P (1958) Nonparametric estimation from incomplete observations. J Am Stat Assoc 53: $457-487$

Kim NK, Kim MJ, Yun SH, Sohn SK, Min JS (1999) Comparative study of transrectal ultrasonography, pelvic computerized tomography, and magnetic resonance imaging in preoperative staging of rectal cancer. Dis Colon Rectum 42: 770-775

Klautke G, Feyerherd P, Ludwig K, Prall F, Foitzik T, Fietkau R (2005) Intensified concurrent chemoradiotherapy with 5-fluorouracil and irinotecan as neoadjuvant treatment in patients with locally advanced rectal cancer. Br J Cancer 92: 1215-1220

Klautke G, Kirchner R, Hopt U, Fietkau R, University of Rostock R, Germany (2001) Continuous Infusion of 5-FU and Weekly Irinotecan with Concurrent Radiotherapy as Neoadjuvant Treatment for Locally Advanced or Recurrent Rectal Cancer. Proc Am Soc Clin Oncol 20(Part I of II): 140a (Abstr.\#555)

Kockerling F, Reymond MA, Altendorf-Hofmann A, Dworak O, Hohenberger W (1998) Influence of surgery on metachronous distant metastases and survival in rectal cancer. I Clin Oncol 16: 324-329
Levine E, Gollins S, Susnerwala S, Haylock B, Saunders M, Myint S, Biswas A, Christie Hospital M, United Kingdom; Glanclwyd Hospital, Glanclwyd, United Kingdom; Royal Preston Hospital, Preston, United Kingdom; Clatterbridge Hospital, Liverpool, United Kingdom (2004) Phase II study of radiotherapy plus concurrent irinotecan (CPT-11) and infusional 5-fluorouracil (5FU) in the treatment of T3-T4 locally advanced inoperable rectal cancer. J Clin Oncol ASCO Annual Meeting Proceedings (Post-Meeting Edition) 22(14S): (July 15 Supplement), 3612

MacFarlane JK, Ryall RD, Heald RJ (1993) Mesorectal excision for rectal cancer. Lancet 341: 457-460

Marijnen C, Peeters K, Putter H, Klein Kranenbarg E, Stiggelbout A, Leer L, Van de Velde C, Group DCC (2005) Long term results, toxicity and quality of life in the TME trial. Gastrointestinal Cancers Symposium ASCO, ASTRO, AGA, SSO, Hollywood, Florida (Abstr.\#166)

Marijnen CA, Kapiteijn E, van de Velde CJ, Martijn H, Steup WH, Wiggers T, Kranenbarg EK, Leer JW (2002) Acute side effects and complications after short-term preoperative radiotherapy combined with total mesorectal excision in primary rectal cancer: report of a multicenter randomized trial. J Clin Oncol 20: $817-825$

Marijnen CA, Nagtegaal ID, Kapiteijn E, Kranenbarg EK, Noordijk EM, van Krieken JH, van de Velde CJ, Leer JW (2003a) Radiotherapy does not compensate for positive resection margins in rectal cancer patients: report of a multicenter randomized trial. Int J Radiat Oncol Biol Phys 55: $1311-1320$

Marijnen CA, Nagtegaal ID, Mulder-Stapel AA, Schrier PI, van de Velde CJ, van Krieken JH, Peltenburg LT (2003b) High intrinsic apoptosis, but not radiation-induced apoptosis, predicts better survival in rectal carcinoma patients. Int J Radiat Oncol Biol Phys 57: 434-443

Mehta VK, Cho C, Ford JM, Jambalos C, Poen J, Koong A, Lin A, Bastidas JA, Young H, Dunphy EP, Fisher G (2003) Phase II trial of preoperative 3D conformal radiotherapy, protracted venous infusion 5-fluorouracil, and weekly CPT-11, followed by surgery for ultrasound-staged T3 rectal cancer. Int J Radiat Oncol Biol Phys 55: $132-137$

Minsky B, O'Reilly E, Wong D, Sharma S, Paty P, Guillem J, Cohen A, Ilson D, Hollywood E, Semple D, Kleban S, Kelsen D, Saltz L (1999) Daily LowDose Irinotecan (CPT-11) Plus Pelvic Irradiation as Preoperative Treatment of Locally Advanced Rectal Cancer. Proc Am Soc Clin Oncol 18: 266a (Abstr.\#1023)

Minsky BD, Cohen AM, Kemeny N, Enker WE, Kelsen DP, Schwartz G, Saltz L, Dougherty J, Frankel J, Wiseberg J (1993) Pre-operative combined 5-FU, low dose leucovorin, and sequential radiation therapy for unresectable rectal cancer. Int J Radiat Oncol Biol Phys 25: $821-827$ Minsky BD, Conti JA, Huang Y, Knopf K (1995) Relationship of acute gastrointestinal toxicity and the volume of irradiated small bowel in patients receiving combined modality therapy for rectal cancer. J Clin Oncol 13: 1409 - 1416

Mitchell E, Anne P, Fry R, Palazzo J, Hauck W, Fishel R, Goldstein S, Isenberg G, Edmunston T, Curran W, Thomas Jefferson Univ, P, PA (2003) Chemoradiation with CPT-11, 5FU in neoadjuvant treatment of locally advanced or recurrent adenocarcinoma of the rectum: A phase I/ II study update. Proc Am Soc Clin Oncol 22: 262 (Abstr.\#1052)

Nagtegaal ID, Marijnen CA, Kranenbarg EK, van de Velde CJ, van Krieken JH (2002) Circumferential margin involvement is still an important predictor of local recurrence in rectal carcinoma: not one millimeter but two millimeters is the limit. Am I Surg Pathol 26: 350-357

Ngan SY, Burmeister BH, Fisher R, Rischin D, Schache DJ, Kneebone A, MacKay JR, Joseph D, Bell A, Goldstein D (2001) Early toxicity from preoperative radiotherapy with continuous infusion 5-fluorouracil for resectable adenocarcinoma of the rectum: a Phase II trial for the TransTasman Radiation Oncology Group. Int J Radiat Oncol Biol Phys 50: $883-887$

NIH consensus conference (1990) Adjuvant therapy for patients with colon and rectal cancer. Jama 264: $1444-1450$

Pahlman L, Glimelius B (1990) Pre- or postoperative radiotherapy in rectal and rectosigmoid carcinoma. Report from a randomized multicenter trial. Ann Surg 211: $187-195$

Rodel C, Grabenbauer GG, Matzel KE, Schick C, Fietkau R, Papadopoulos T, Martus P, Hohenberger W, Sauer R (2000) Extensive surgery after high-dose preoperative chemoradiotherapy for locally advanced recurrent rectal cancer. Dis Colon Rectum 43: 312 - 319

Rodel C, Grabenbauer GG, Papadopoulos T, Hohenberger W, Schmoll HJ, Sauer R (2003) Phase I/II trial of capecitabine, oxaliplatin, and radiation for rectal cancer. J Clin Oncol 21: 3098-3104

Rothenberg ML, Eckardt JR, Kuhn JG, Burris III HA, Nelson J, Hilsenbeck SG, Rodriguez GI, Thurman AM, Smith LS, Eckhardt SG, Weiss GR, 
Elfring GL, Rinaldi DA, Schaaf LJ, Von Hoff DD (1996) Phase II trial of irinotecan in patients with progressive or rapidly recurrent colorectal cancer. J Clin Oncol 14: 1128-1135

Saltz LB, Cox JV, Blanke C, Rosen LS, Fehrenbacher L, Moore MJ, Maroun JA, Ackland SP, Locker PK, Pirotta N, Elfring GL, Miller LL (2000) Irinotecan plus fluorouracil and leucovorin for metastatic colorectal cancer. Irinotecan Study Group. N Engl J Med 343: 905-914

Sanfilippo NJ, Crane CH, Skibber J, Feig B, Abbruzzese JL, Curley S, Vauthey JN, Ellis LM, Hoff P, Wolff RA, Brown TD, Cleary K, Wong A, Phan T, Janjan NA (2001) T4 rectal cancer treated with preoperative chemoradiation to the posterior pelvis followed by multivisceral resection: patterns of failure and limitations of treatment. Int J Radiat Oncol Biol Phys 51: $176-183$

Sauer R, Becker H, Hohenberger W, Rodel C, Wittekind C, Fietkau R, Martus P, Tschmelitsch J, Hager E, Hess CF, Karstens JH, Liersch T, Schmidberger H, Raab R (2004) Preoperative versus postoperative chemoradiotherapy for rectal cancer. $N$ Engl J Med 351: $1731-1740$

Saunders M, Dische S, Barrett A, Harvey A, Griffiths G, Palmar M (1999) Continuous, hyperfractionated, accelerated radiotherapy (CHART) versus conventional radiotherapy in non-small cell lung cancer: mature data from the randomised multicentre trial. CHART Steering committee. Radiother Oncol 52: 137-148

Stockholm trial (1996) Randomized study on preoperative radiotherapy in rectal carcinoma. Stockholm Colorectal Cancer Study Group. Ann Surg Oncol 3: $423-430$
Suwinski R, Wydmanski J, Pawelczyk I, Starzewski J (2006) A pilot study of accelerated preoperative hyperfractionated pelvic irradiation with or without low-dose preoperative prophylactic liver irradiation in patients with locally advanced rectal cancer. Radiother Oncol May 24 [Epub ahead of print]

Swedish Rectal Cancer Trial (SRCT) (1997) Improved survival with preoperative radiotherapy in resectable rectal cancer. Swedish Rectal Cancer Trial. N Engl J Med 336: $980-987$

Tepper JE, O'Connell M, Niedzwiecki D, Hollis DR, Benson III AB, Cummings B, Gunderson LL, Macdonald JS, Martenson JA, Mayer RJ (2002) Adjuvant therapy in rectal cancer: analysis of stage, sex, and local control - final report of intergroup 0114. J Clin Oncol 20: 1744-1750

Turrisi III AT, Kim K, Blum R, Sause WT, Livingston RB, Komaki R, Wagner H, Aisner S, Johnson DH (1999) Twice-daily compared with once-daily thoracic radiotherapy in limited small-cell lung cancer treated concurrently with cisplatin and etoposide. N Engl J Med 340: 265-271

Van Cutsem E, Labianca R, Hossfeld D, Bodoky G, Roth A, Aranda E, Nordlinger B, Assadourian S, Wang K, Cunningham D (2005) Randomized phase III trial comparing infused irinotecan/5-fluorouracil (5-FU)/folinic acid (IF) versus 5-FU/FA (F) in stage III colon cancer patients (pts). (PETACC 3). J Clin Oncol, ASCO Annual Meeting Proceedings 23: 8

Voelter V, Stupp R, Matter M, Gillet M, Bouzourene H, Leyvraz S, Coucke P (2003) Preoperative hyperfractionated accelerated radiotherapy (HART) and concomitant CPT-11 in locally advanced rectal carcinoma: a phase study. Int J Radiat Oncol Biol Phys 56: 1288-1294 